\title{
Bronchodilators use in patients with COPD
}

This article was published in the following Dove Press journal:

International Journal of COPD

I September 2015

Number of times this article has been viewed

\author{
Yaa-Hui Dong ${ }^{1,2, *}$ \\ Chia-Lin Hsu ${ }^{3,4, *}$ \\ Ying-Ying $\mathrm{Li}^{5}$ \\ Chia-Hsuin Chang ${ }^{6,7}$ \\ Mei-Shu Lai ${ }^{2,7}$ \\ 'Division of Pharmacoepidemiology \\ and Pharmacoeconomics, Department \\ of Medicine, Brigham and Women's \\ Hospital, Harvard Medical School, \\ Boston, MA, USA; ${ }^{2}$ Center of \\ Comparative Effectiveness Research, \\ National Center of Excellence for \\ Clinical Trial and Research, National \\ Taiwan University Hospital, Taipei, \\ Taiwan; ${ }^{3}$ Division of Pulmonary \\ Medicine, Department of Internal \\ Medicine, National Taiwan University \\ Hospital, College of Medicine, Taipei, \\ Taiwan; ${ }^{4}$ Graduate Institute of Clinical \\ Medicine, College of Medicine, \\ National Taiwan University, Taipei, \\ Taiwan; ${ }^{5}$ Department of Pharmacy, \\ Sijhih Cathay General Hospital, New \\ Taipei City, Taiwan; ${ }^{6}$ Department of \\ Internal Medicine, National Taiwan \\ University Hospital, Taipei, Taiwan; \\ ${ }^{7}$ Graduate Institute of Epidemiology \\ and Preventive Medicine, College \\ of Public Health, National Taiwan \\ University, Taipei, Taiwan \\ *These authors contributed equally \\ to this work
}

Background: Bronchodilators are commonly used as maintenance and rescue therapy in patients with COPD. We aimed to examine the prescribing patterns of bronchodilators in clinical practice. Methods: We identified patients with COPD who initiated oral or inhaled bronchodilators between 2001 and 2010 from the Taiwan National Health Insurance Research Database. We followed the patients for 1 year. For bronchodilator prescriptions, we classified the treatments based on medication classes and regimens (oral bronchodilators alone, oral and inhaled bronchodilators in combination, or inhaled bronchodilators alone). For inhaled bronchodilator prescriptions, we further classified the treatments as short-acting bronchodilators alone, short-acting and long-acting bronchodilators in combination, and long-acting bronchodilators alone. We evaluated the prescribing patterns and the change with time, in different physician specialists, and in different hospital accreditation levels.

Results: Among a cohort of 4,387 study-eligible patients, we identified 21,235 bronchodilator prescriptions for the analysis. The majority of prescriptions were oral xanthines or beta- 2 agonists (62.63\% and $47.54 \%$, respectively) rather than prescriptions for inhaled bronchodilators (less than $10 \%$ ). Nearly $80 \%$ of prescriptions were oral bronchodilator alone regimens. Use of oral bronchodilators declined with time and varied with health care providers, which were most commonly prescribed by non-chest specialists and in primary care clinics. Despite limited use of inhaled bronchodilators, it was noted that short-acting bronchodilators alone regimens accounted for $60 \%$ of the inhaled bronchodilator prescriptions.

Conclusion: Excessive use of oral and short-acting bronchodilators is noted in general practice. Further research and education programs are warranted to decrease inadequate oral bronchodilators and optimize inhaled treatments in the management of patients with COPD.

Keywords: bronchodilators, chronic obstructive pulmonary disease, prescribing patterns Taiwan

\section{Introduction}

Currently, COPD is the ninth leading cause of mortality worldwide accounting for more than $3 \%$ of total deaths. ${ }^{1}$ Patients with COPD have a threefold increased risk of overall death and a twofold increased risk of cardiovascular death and morbidity compared with those without COPD. ${ }^{2,3}$ Patients with COPD are susceptible not only to pulmonary, musculoskeletal, and psychological morbidities, but also undergo higher hospitalization, and live a poor quality of life. ${ }^{4}$ Given the substantial burden of disease globally, management of COPD is an important public health issue.

The Global Initiative for Chronic Obstructive Lung Disease (GOLD) guidelines recommend that bronchodilators medications are the mainstay for management of COPD, which could be administered via inhaled or oral routes. ${ }^{4}$ In terms of effectiveness and safety profiles, inhaled bronchodilators are preferred to oral bronchodilators. Furthermore, inhaled long-acting bronchodilators are more convenient and more effective than the inhaled short-acting bronchodilators. Several investigators have explored the use of bronchodilators in patients with COPD in real clinical settings
Correspondence: Chia-Hsuin Chang Department of Internal Medicine, National Taiwan University Hospital, 7, Chung-Shan South Road, Taipei 10002 , Taiwan

Tel +886223123456

Fax +886223920456

Email chiahsuin123@yahoo.com.tw
International Journal of COPD 2015:10 1769-1779 
and compared the adherence to the guidelines, which showed variations across geographic areas and with time. ${ }^{5-11}$ Moreover, previous research indicated that health care providers have apparent impacts on the patterns of care for a variety of diseases, including COPD. ${ }^{12-14}$

COPD also carries a major socioeconomic burden in Asia, with an overall estimated prevalence of $6.3 \%$ across nine Asia-Pacific territories. ${ }^{11}$ However, few studies have addressed appropriateness of pharmaceutical care in these areas. In order to identify and analyze the potential problems in bronchodilator utilization, and to improve the optimal quality of drug therapy in Taiwan, we conducted a population-based study to assess the prescribing patterns of bronchodilators, evaluated the change with time and in different health care providers, and examined the inconsistency with the GOLD guidelines recommendations.

\section{Methods}

\section{Data source and source population}

A single-payer and mandatory National Health Insurance program was initiated in Taiwan in 1995, with an enrollment rate of $98.4 \%$ in 2007 . The National Health Insurance Research Database is a research dataset developed by the National Health Research Institute, and is linked with demographic and enrollment records, hospital admissions, outpatient visits, and pharmacy dispensing claims data from hospitals, outpatient clinics, and community pharmacies. The Longitudinal Health Insurance Database 2005 comprises a random sample of one million individuals from the National Health Insurance Research Database with longitudinally linked data for individuals starting from 1997, which is updated annually. The source population of this study included all beneficiaries from the Longitudinal Health Insurance Database 2005. The study protocol was approved by the National Taiwan University Hospital Research Ethics Committee (approval number: 201308065W).

\section{Study population}

From the source population, we identified patients who initiated oral or inhaled bronchodilators in outpatient visits between January 1, 2001 and December 31, 2010. We did not include prescriptions in the hospitalization periods given that bronchodilators (especially oral and inhaled, short-acting forms) may be prescribed for acute, unspecific respiratory conditions other than COPD in the inpatient settings. The oral bronchodilators included beta- 2 agonists and xanthines. The inhaled bronchodilators included short-acting beta- 2 agonists (SABAs), short-acting muscarinic antagonists (SAMAs), long-acting beta-2 agonists (LABAs), fixed dose combinations of LABA and inhaled corticosteroids (LABA/ICS FDCs), and long-acting muscarinic antagonists (LAMAs). The Anatomical Therapeutic Chemical classification system codes for individual medications are listed in Table S1. Initiation was defined as being free from any prescription of oral or inhaled bronchodilators 1 year prior to the first prescription (ie, the index dates). Exclusion criteria included 1) patients less than 18 years or more than 100 years of age, and 2) patients who did not have continuous insurance coverage 1 year before drug initiation, defined as a lack of inpatient or outpatient visits 1 year before the index dates. Patients with COPD were identified with any corresponding diagnoses in the inpatient and outpatient visits 1 year before or on the index dates (International Classification of Diseases, 9th Revision, Clinical modification [ICD-9-CM] codes 491, 492, 496). Patients concurrently having COPD and asthma diagnoses (ICD-9-CM code 493) were excluded from the study. To minimize coding errors in COPD diagnoses, we further restricted the analyses to those receiving pulmonary function tests between 1 year before and 1 year after the bronchodilator initiation. Patient comorbidities were ascertained based on inpatient and outpatient diagnosis record files within 1 year before the index dates (ICD-9-CM codes for comorbidity identification are provided in Table S2). Resource utilization was also calculated based on the records of hospital admissions and outpatient visits within 1 year before the index date.

\section{Medication exposure}

We followed the patients for 1 year from the index dates. We calculated the number of bronchodilator prescriptions during this study period and classified bronchodilator treatments according to medication classes and regimens (oral bronchodilators alone, oral and inhaled bronchodilators in combination, or inhaled bronchodilators alone). For inhaled bronchodilator prescriptions, which included at least one inhaled bronchodilator in one prescription, we further classified the treatments as short-acting bronchodilators alone, short-acting and long-acting bronchodilators in combination, or long-acting bronchodilators alone. In addition, we classified inhaled bronchodilators as different device types, including nebulizers, meter-dose inhalers, and dry-powder inhalers.

\section{Statistical analysis}

For the study cohort, we tabulated the distribution of demographic characteristics at baseline. We calculated the proportion of prescriptions belonging to a particular 
medication class or regimen during the study period. For oral bronchodilator-based regimens, we explored the accompanying respiratory diagnoses and calculated the cumulative prescribed durations. To examine the potential variation in the prescribing patterns with time and health care providers, the prescriptions were stratified based on the years of index dates (2001-2003, 2004-2006, and 2007-2010), physician specialists (chest, internal medicine, family medicine, and others), and hospital accreditation levels (medical centers, metropolitan hospitals, district hospitals, or primary care clinics). The Cochran-Armitage trend test was applied to assess whether there was a significant, temporal trend for oral bronchodilators and inhaled bronchodilators, respectively. We finally calculated number of prescriptions for different bronchodilators per individual, which served as an indicator of adherence. We also evaluated the relation between bronchodilator use and hospitalizations during the 1-year follow-up using a multivariate logistic regression model with other patients' characteristics, including age, sex, index years, and comorbidities and resource utilization at baseline. We estimated the adjusted odds ratio (OR) with $95 \%$ confidence intervals (CIs). All the statistical analyses were carried out using SAS 9.3 (SAS Institute Inc., Cary, NC, USA).

\section{Results}

The eligible cohort comprised 4,387 patients with COPD who initiated bronchodilators (Figure 1). The demographic characteristics of these bronchodilator initiators are summarized in Table 1. The initiators had a mean (SD) age of 61.18 (15.86) years, with $73.03 \%$ of males and common

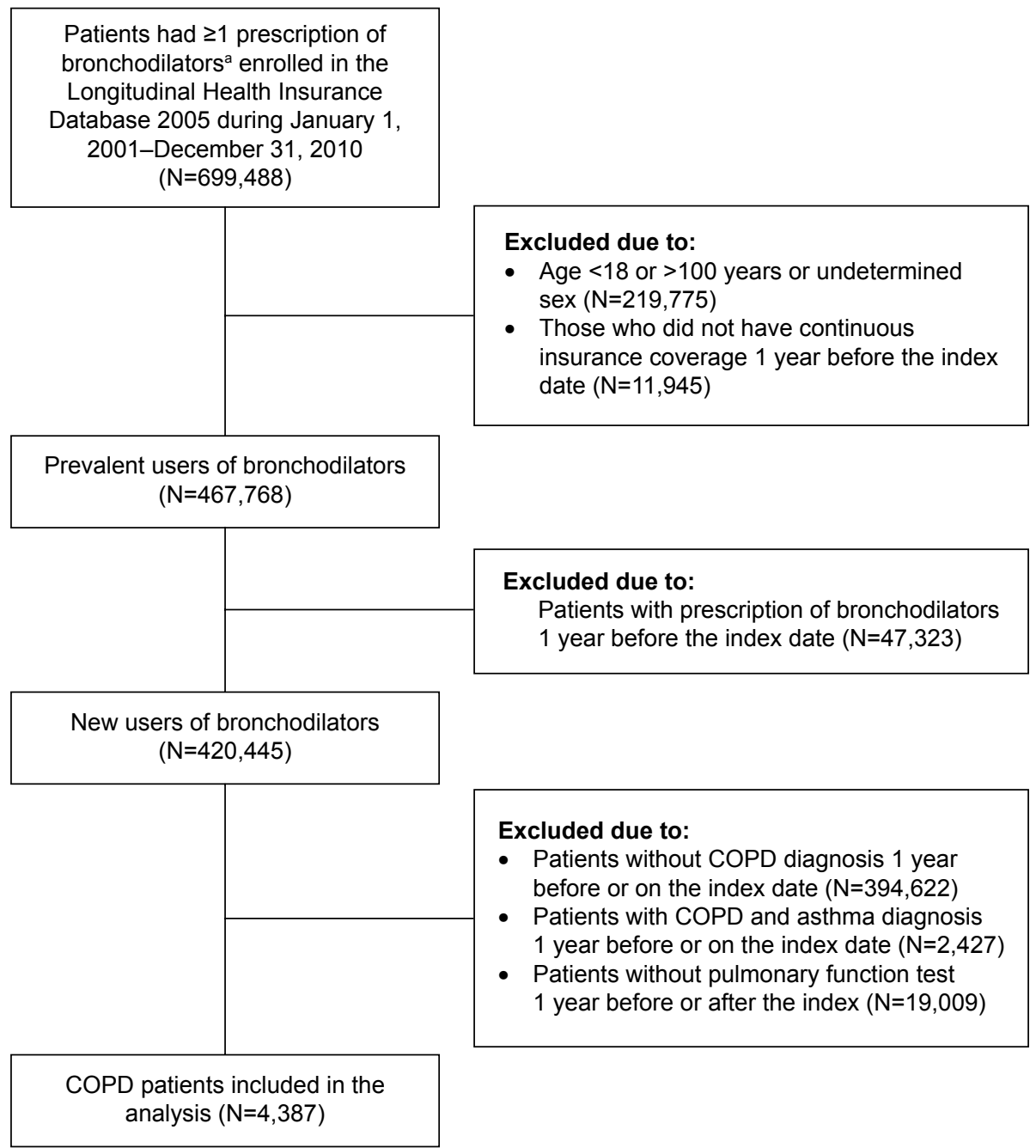

Figure I Flowchart of study cohort assembly.

Notes: aBronchodilators included oral and inhaled forms: I) oral forms: xanthines and beta-2 agonists, 2) inhaled forms: short-acting beta-2 agonists (SABAs), short-acting muscarinic antagonists (SAMAs), long-acting beta-2 agonists (LABAs), long-acting muscarinic antagonists (LAMAs), and fixed dose combinations of LABA and inhaled corticosteroids (ICS) (LABA/ICS FDCs).

Abbreviation: FDC, fixed dose combination. 
Table I Demographic characteristics of bronchodilator initiators at baseline

\begin{tabular}{|c|c|}
\hline & $\begin{array}{l}\text { Bronchodilator } \\
\text { initiators }(\mathrm{N}=4,387)\end{array}$ \\
\hline Age on the index dates, mean (SD) & $61.18(15.86)$ \\
\hline Male, \% & 73.03 \\
\hline \multicolumn{2}{|l|}{ Years of index dates, \% } \\
\hline $200 I-2003$ & 47.71 \\
\hline 2004-2006 & 27.70 \\
\hline $2007-2010$ & 24.60 \\
\hline \multicolumn{2}{|l|}{ Comorbidities, \% } \\
\hline Hypertension & 29.82 \\
\hline Hypertensive heart and renal disease & 14.75 \\
\hline Ischemic heart disease/angina & 18.37 \\
\hline Myocardial infarction & 1.19 \\
\hline Coronary revascularization & 0.75 \\
\hline Cardiac dysrhythmia & 8.96 \\
\hline Atrial fibrillation & 2.17 \\
\hline Congestive heart failure & 5.65 \\
\hline Cerebrovascular disease & 10.78 \\
\hline Ischemic/hemorrhagic stroke & 8.00 \\
\hline Transient ischemic attack & 1.69 \\
\hline Diabetes mellitus & 15.14 \\
\hline Pneumonia, influenza, and acute bronchitis & 35.74 \\
\hline Rheumatoid arthritis/osteoarthritis & 18.28 \\
\hline Any cancer (except lung cancer) & 6.38 \\
\hline Lung cancer & 2.26 \\
\hline Depressive disorder & 4.65 \\
\hline \multicolumn{2}{|l|}{ Resource utilization } \\
\hline Hospitalization, \% & 27.42 \\
\hline Hospitalization due to COPD episodes, \% & 6.86 \\
\hline $\begin{array}{l}\text { Hospitalization due to cardiovascular } \\
\text { episodes }{ }^{\mathrm{a}} \%\end{array}$ & 13.20 \\
\hline Number of outpatient visits, mean (SD) & $24.38(19.83)$ \\
\hline $\begin{array}{l}\text { Number of outpatient visits due to COPD } \\
\text { episodes, mean (SD) }\end{array}$ & $1.05(2.49)$ \\
\hline $\begin{array}{l}\text { Number of outpatient visits due to } \\
\text { cardiovascular episodes }{ }^{a} \text {, mean (SD) }\end{array}$ & $4.43(7.65)$ \\
\hline
\end{tabular}

Notes: ${ }^{a}$ Cardiovascular episodes included hypertension, hypertensive heart/renal disease, ischemic heart disease/angina, myocardial infarction, coronary revascularization, cardiac dysrhythmia, atrial fibrillation, congestive heart failure, cerebrovascular disease, ischemic/hemorrhagic stroke, and transient ischemic attack.

cardiovascular comorbidities. There were $27.42 \%$ of initiators experiencing hospitalization, and the mean (SD) number of outpatient visits due to any causes were 24.38 (18.83). The most frequently prescribed bronchodilators on the index date were oral xanthines $(61.36 \%$ of initiators) and beta- 2 agonists (46.68\%); these frequencies were substantially higher than those of the inhaled bronchodilators, including SABAs (11.06\%), SAMAs (9.30\%), LABA/ICS FDCs $(1.89 \%)$, LAMAs (1.23\%), and LABAs $(0.50 \%)$.

As shown in Table 2, there were 21,235 bronchodilator prescriptions during the 1-year follow-up period. Use of oral xanthines and beta- 2 agonists accounted for $62.63 \%$ and $47.54 \%$ of the prescriptions, respectively, which remained substantially higher than any use of inhaled bronchodilators.
SABAs and SAMAs were the most commonly used inhaled bronchodilators, making up $9.84 \%$ and $8.78 \%$ of the proportions, individually. There was an approximate two- to threefold increase in the use of LABAs, LABA-ICS FDCs, and LAMAs during the follow-up period compared with initiation; however, all the proportions remained less than 5\%. Notably, $88.61 \%$ and $80.79 \%$ of the prescriptions were oral bronchodilator based and oral bronchodilator alone regimens, respectively. Among the oral bronchodilator-based regimens (19,657 prescriptions), the most commonly accompanying respiratory diagnosis was COPD $(60.48 \%)$, followed by acute upper respiratory infection $(20.25 \%)$ and pneumonia (4.47\%). The mean (SD) cumulative prescribed durations for oral bronchodilator-based regimens were 64.88 (SD: 92.31) days per patient within 1 year. Among 4,096 inhaled bronchodilator prescriptions, $61.62 \%$ were short-acting bronchodilator alone regimens and $55.44 \%$ were delivered via metered-dose inhalers (Table S3).

The change in prescribing patterns with time varied for individual medication classes. The proportions of SABAs, SAMAs, LAMAs, and LABA/ICS FDCs increased with time, with the most apparent change in LAMAs (from $0.01 \%$ during 2001-2003 to 7.93\% during 2007-2010). However, the proportions of oral xanthines, oral beta- 2 agonists, and LABAs decreased with time, with the most evident change in LABAs (from 2.02\% during 2001-2003 to 0.04\% during 2007-2010). There was a decreasing temporal trend for oral bronchodilator alone regimens and short-acting bronchodilator alone regimens, although the figures were still high, accounting for $71.89 \%$ of the total bronchodilator prescriptions and $46.68 \%$ of the inhaled bronchodilator prescriptions during 2007-2010, individually. In terms of inhaled device types, use of meter-dose inhalers decreased with time (from $69.37 \%$ during 2001-2003 to 38.69\% during 2007-2010), whereas nebulizers and dry-powder inhalers increased with time (from $17.05 \%$ and $20.86 \%$ during 2001-2003 to $29.26 \%$ and $41.17 \%$ during 2007-2010, respectively) (Table S3). In general, oral alone bronchodilator regimens significantly decreased with time (from $83.77 \%$ during $2001-2003$ to $71.89 \%$ during $2007-2010$ ) and inhaled-based bronchodilator regimens significantly increased with time (from 16.23\% during 2001-2003 to $28.11 \%$ during 2007-2010), with a $P$-value of less than 0.0001 , respectively.

It was noted that the prescribing patterns apparently differed among physician specialists. Non-chest specialists, including family medicine, internal medicine, and others (mainly otolaryngology), prescribed more oral beta- 2 
Table 2 Number and proportion of bronchodilator prescriptions over I year in total bronchodilator initiators and stratified by the years of index dates

\begin{tabular}{|c|c|c|c|c|}
\hline & \multirow{2}{*}{$\begin{array}{l}\text { Total } \\
\text { initiators }\end{array}$} & \multicolumn{3}{|c|}{ Years of index dates } \\
\hline & & $200 I-2003$ & 2004-2006 & $2007-2010$ \\
\hline Number of total bronchodilator prescriptions & 21,235 & 11,162 & 5,712 & 4,451 \\
\hline \multicolumn{5}{|l|}{ Pattern of bronchodilator treatments } \\
\hline \multicolumn{5}{|l|}{ By medication classes ${ }^{\mathrm{a}}$, \% } \\
\hline Oral xanthines & 62.63 & 65.70 & 61.71 & 56.12 \\
\hline Oral beta-2 agonists & 47.54 & 50.07 & 47.99 & 40.62 \\
\hline SABAs & 9.84 & 8.14 & 10.21 & $|3.6|$ \\
\hline SAMAs & 8.78 & 8.68 & 8.05 & 9.98 \\
\hline LABAs & 1.14 & 2.02 & 0.26 & 0.04 \\
\hline LABA/ICS FDCs & 4.41 & 2.54 & 4.69 & 8.76 \\
\hline LAMAs & 2.23 & 0.01 & 2.12 & 7.93 \\
\hline \multicolumn{5}{|l|}{ By regimens ${ }^{b}, \%$} \\
\hline Oral bronchodilators alone & 80.79 & 83.77 & 81.92 & 71.89 \\
\hline Oral and inhaled bronchodilators in combination & 7.82 & 4.80 & 7.39 & 15.95 \\
\hline Inhaled bronchodilators alone & 11.39 & 11.43 & 10.70 & 12.15 \\
\hline Number of inhaled bronchodilator prescriptions & 4,096 & 1,812 & I,033 & $|, 25|$ \\
\hline \multicolumn{5}{|l|}{ Pattern of inhaled bronchodilator treatments } \\
\hline \multicolumn{5}{|l|}{ By regimens ${ }^{\mathrm{b}}, \%$} \\
\hline Short-acting bronchodilators alone & 61.62 & 71.85 & 61.76 & 46.68 \\
\hline Short-acting and long-acting bronchodilators in combination & 31.23 & 21.03 & 30.78 & 46.36 \\
\hline Long-acting bronchodilators alone & 7.15 & 7.12 & 7.45 & 6.95 \\
\hline
\end{tabular}

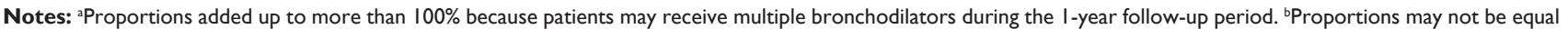
to $100 \%$ due to rounding.

Abbreviations: FDCs, fixed dose combinations; LABAs, long-acting beta-2 agonists; LAMAs, long-acting muscarinic antagonists; SABAs, short-acting beta agonists; SAMAs, short-acting muscarinic antagonists; ICS, inhaled cortiocsteroids.

agonists, but fewer xanthines and inhaled bronchodilators when compared with the chest specialists. Non-chest specialists were also more likely to prescribe oral bronchodilator alone regimens and short-acting bronchodilator alone regimens than chest specialists (Table 3). In terms of hospital accreditation levels, physicians in primary care clinics were most likely to prescribe oral beta-2 agonists, followed by physicians in district hospitals, in metropolitan hospitals, and in medical centers. In contrast, physicians in primary care clinics are least likely to prescribe oral xanthines and inhaled bronchodilators, followed by physicians in district hospitals, in metropolitan hospitals, and in medical centers. In line with the prescribing patterns of individual medication classes, use of oral bronchodilator alone regimens and shortacting bronchodilator alone regimens was most prevalent in primary care clinics, and declined with the increase of hospital accreditation levels (Table 4).

On average, patients received 4.86 prescriptions for any bronchodilators during the 1-year of follow-up, with 4.48, 0.64 , and 0.36 prescriptions for oral bronchodilators, inhaled short-acting bronchodilators, and inhaled long-acting bronchodilators, respectively. A total of 1,289 patients (29.38\%) experienced hospitalization during the 1-year follow-up period. There was a slightly, significantly increased risk of hospitalization associated with number of any bronchodilators (adjusted OR: 1.05 [95\% CI: 1.03-1.06]), oral bronchodilators (adjusted OR: 1.04 [95\% CI: 1.03-1.06]), and inhaled short-acting bronchodilators (adjusted OR: 1.12 [95\% CI: 1.08-1.17]). In contrast, no excess risk of hospitalization was associated with number of inhaled long-acting bronchodilators (adjusted OR: 0.98 [95\% CI: 0.94-1.03]) (Table S4).

\section{Discussion}

This study suggests that, in the management of COPD patients in Taiwan, the vast majority of prescriptions were oral rather than inhaled bronchodilators, and monotherapy of oral bronchodilators dominated all the treatments during the 1-year follow-up period. Use of oral bronchodilators declined with time and varied with health care providers, and were most commonly prescribed by the non-chest specialists and in primary care clinics. These findings imply that additional strategies should be employed to improve clinical practice in the management of patients with COPD.

Use of bronchodilators has been noted to follow various patterns across countries and with time. A US research, using the Veteran Affairs administrative data of 1999-2003, demonstrated that SABA and SAMA were the most frequently prescribed bronchodilators, which were used by $80 \%$ and $70 \%$ of 
Table 3 Number and proportion of bronchodilator prescriptions over I year stratified by physician specialists

\begin{tabular}{|c|c|c|c|c|}
\hline & $\begin{array}{l}\text { Family } \\
\text { medicine }\end{array}$ & $\begin{array}{l}\text { Internal medicine } \\
\text { except chest }\end{array}$ & Chest & Others \\
\hline Number of total bronchodilator prescriptions & $1,67 \mid$ & 6,458 & 9,228 & 3,968 \\
\hline \multicolumn{5}{|l|}{ Pattern of bronchodilator treatments } \\
\hline \multicolumn{5}{|l|}{ By medication classes ${ }^{\mathrm{a}}, \%$} \\
\hline Oral xanthines & 55.60 & 63.84 & 71.26 & 43.55 \\
\hline Oral beta- 2 agonists & 57.27 & 47.09 & 40.78 & 59.90 \\
\hline SABAs & 5.63 & 7.77 & 11.00 & 12.27 \\
\hline SAMAs & 2.69 & 5.36 & 12.35 & 8.62 \\
\hline LABAs & 0.00 & 0.79 & 2.05 & 0.08 \\
\hline LABA/ICS FDCs & 0.66 & 1.87 & 8.33 & 1.01 \\
\hline LAMAs & 0.06 & 1.25 & 4.14 & 0.28 \\
\hline \multicolumn{5}{|l|}{ By regimens $^{b}, \%$} \\
\hline Oral bronchodilators alone & 92.40 & 87.40 & 71.65 & 86.42 \\
\hline Oral and inhaled bronchodilators in combination & 3.77 & 5.62 & 9.89 & 8.29 \\
\hline Inhaled bronchodilators alone & 3.83 & 6.98 & 18.45 & 5.29 \\
\hline Number of inhaled bronchodilator prescriptions & 127 & 814 & 2,616 & 539 \\
\hline \multicolumn{5}{|l|}{ Pattern of inhaled bronchodilator treatments } \\
\hline \multicolumn{5}{|l|}{ By regimens $^{b}, \%$} \\
\hline Short-acting bronchodilators alone & 90.55 & 70.88 & 51.49 & 89.98 \\
\hline Short-acting and long-acting bronchodilators in combination & 9.45 & 24.32 & 39.37 & 7.24 \\
\hline Long-acting bronchodilators alone & 0.00 & 4.79 & 9.14 & 2.78 \\
\hline
\end{tabular}

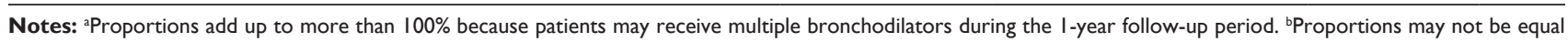
to $100 \%$ due to rounding.

Abbreviations: FDCs, fixed dose combinations; LABAs, long-acting beta-2 agonists; LAMAs, long-acting muscarinic antagonists; SABAs, short-acting beta agonists; SAMAs, short-acting muscarinic antagonists; ICS, inhaled corticosteroids.

COPD patients, respectively. ${ }^{5}$ Two research studies conducted in the Netherlands and Italy (using hospital-based data of 2005-2009 and 2009, respectively) indicated that LAMA and LABA/ICS FDC were the most prevalent bronchodilators, with more than $60 \%$ of COPD patients receiving either drug. ${ }^{6,7}$ All of these aforementioned studies showed that oral bronchodilators would not be the central treatment, with less than $30 \%$ of COPD patients taking xanthines.$^{6-10}$ In contrast, one population survey study conducted in nine Asia-Pacific territories in 2012 noted that oral treatment was the major

Table 4 Number and proportion of bronchodilator prescriptions over I year stratified by hospital accreditation levels

\begin{tabular}{|c|c|c|c|c|}
\hline & $\begin{array}{l}\text { Primary care } \\
\text { clinics }\end{array}$ & $\begin{array}{l}\text { District } \\
\text { hospitals }\end{array}$ & $\begin{array}{l}\text { Metropolitan } \\
\text { hospitals }\end{array}$ & $\begin{array}{l}\text { Medical } \\
\text { centers }\end{array}$ \\
\hline Number of total bronchodilator prescriptions & 4,188 & 4,448 & 6,668 & 6,021 \\
\hline \multicolumn{5}{|l|}{ Pattern of bronchodilator treatments } \\
\hline \multicolumn{5}{|l|}{ By medication classes ${ }^{\mathrm{a}}, \%$} \\
\hline Oral xanthines & 43.46 & 64.14 & 67.41 & 69.56 \\
\hline Oral beta- 2 agonists & 67.77 & 47.98 & 43.21 & 37.95 \\
\hline SABAs & 2.55 & 10.39 & 11.41 & 12.76 \\
\hline SAMAs & 1.10 & 6.25 & 10.36 & 14.25 \\
\hline LABAs & 0.00 & 0.36 & 1.14 & 2.51 \\
\hline LABA/ICS FDCs & 1.19 & 2.34 & 4.66 & 7.91 \\
\hline LAMAs & 1.03 & 1.33 & 1.92 & 4.07 \\
\hline \multicolumn{5}{|l|}{ By regimens } \\
\hline Oral bronchodilators alone & 95.06 & 84.42 & 79.45 & 69.67 \\
\hline Oral and inhaled bronchodilators in combination & 2.27 & 6.65 & 8.01 & 12.34 \\
\hline Inhaled bronchodilators alone & 2.67 & 8.93 & 12.54 & 17.99 \\
\hline Number of inhaled bronchodilator prescriptions & 207 & 693 & 1,370 & 1,826 \\
\hline \multicolumn{5}{|l|}{ Pattern of inhaled bronchodilator treatments } \\
\hline \multicolumn{5}{|l|}{ By regimens ${ }^{b}, \%$} \\
\hline Short-acting bronchodilators alone & 56.04 & 75.76 & 64.01 & 55.09 \\
\hline Short-acting and long-acting bronchodilators in combination & 40.10 & 17.89 & 27.96 & 37.73 \\
\hline Long-acting bronchodilators alone & 3.86 & 6.35 & 8.03 & 7.17 \\
\hline
\end{tabular}

Notes: aProportions add up to more than $100 \%$ because patients may receive multiple bronchodilators during the I-year follow-up period. bProportions may not be equal to $100 \%$ due to rounding.

Abbreviations: FDCs, fixed dose combinations; LABAs, long-acting beta-2 agonists; LAMAs, long-acting muscarinic antagonists; SABAs, short-acting beta agonists; SAMAs, short-acting muscarinic antagonists; ICS, inhaled corticosteroids. 
type of pharmaceutical care. Among 4,289 COPD patients, around $65 \%$ and $35 \%$ of individuals used oral dosage forms and inhaled devices, respectively. ${ }^{11}$ Similar to these findings, our results addressed a potentially excessive use of oral xanthines and beta- 2 agonists $(60 \%$ and $50 \%$ of the bronchodilator prescriptions, respectively). In terms of monotherapy of oral bronchodilators, the proportions were even nearly $80 \%$, although the figures decreased with time.

We proposed several factors to explain these observations. First, oral bronchodilators are less expensive. For example, in Taiwan, oral salbutamol costs less than 0.05 US dollars per 2-4 mg per tablet. However, inhaled salbutamol and salmeterol cost at least 0.2 US dollars per $100 \mathrm{mcg}$ and per 25 mcg per puff, respectively. The Asian Pacific COPD Roundtable Group, a taskforce of expert respirologists from the Asia-Pacific region, has also found that physicians may consider oral bronchodilators as an alternative to inhaled treatments in some Asia-Pacific settings, due to the price issue. ${ }^{15}$ Second, although all of the bronchodilators are reimbursed by the National Health Insurance program, regardless of administered routes in Taiwan, given the cost consideration, use of inhaled bronchodilators rather than oral ones usually requires more clinical evidence including pulmonary function tests to ensure the appropriate indication. However, for those with difficulties or reluctance to have pulmonary function tests, this may be a partial barrier for them to receive inhaled medications. Third, in terms of skills and time needed to take an oral pill and take an inhaled dose, patients may prefer oral rather than inhaled forms. ${ }^{16}$ One study demonstrated that patients had better adherence to oral theophylline than inhaled anti-inflammatory medications. ${ }^{17}$ Also, the use of inhaled bronchodilators requires additional device education for clinical physicians. For management of COPD, the adequate use of inhaled medications would be beneficial to clinical outcomes and medical resource utilization. ${ }^{4}$ Sincere and determined efforts are necessary to improve prescribing patterns of bronchodilators.

Besides geographical differences, economic considerations, and patients' compliance, research indicated that type of health care providers has a substantial impact on patterns of care in a variety of diseases, including COPD ${ }^{12-14}$ In view of appropriate use of inhaled short-acting and long-acting bronchodilators for patients with different severity, two research studies demonstrated that non-chest specialists (including internal medicine, family medicine, and primary care) are less likely to adhere to the GOLD guidelines recommendations when compared with the chest specialists. ${ }^{13,14}$ In our study, use of oral bronchodilator alone regimens was more common in non-chest specialists than in chest specialists.
Also, the proportions were highest in the primary care clinics and declined with the increase of hospital accreditation levels. All these findings agreed with previous reports which found that primary care physicians may have less familiarity with and less awareness of the treatment principles in the guidelines when compared with chest specialists. ${ }^{14,18,19}$ For physicians with poor adherence to GOLD guidelines, our results suggest to develop specific strategies and education programs in the future.

Despite limited use of inhaled bronchodilators, we observed an apparent temporal trend in the use of long-acting bronchodilators. There was an increasing use of LAMAs and LABA-ICS FDCs but a decreasing use of LABAs. These data are consistent with drug development histories and changes in global manufacturing market shares. ${ }^{20,21}$ These data are also parallel with approval years of inhaled longacting bronchodilators in Taiwan (LABAs, 1996; LABA-ICS FDCs, 2001; LAMAs, 2003; Table S1). In addition, our study found that nearly $60 \%$ of inhaled bronchodilator prescriptions were short-acting bronchodilator alone regimens during the 1-year follow-up period. The GOLD guidelines recommend that monotherapy of short-acting bronchodilators is only indicated for patients with mild symptoms (ie, Group A patients). ${ }^{4}$ Due to lack of pulmonary function data, we could not definitively determine the appropriateness of their use. However, proportions of patients hospitalized and mean (SD) number of outpatient visits due to COPD episodes at baseline were approximately $6.86 \%$ and $1.05 \%$ (2.49), which suggested that disease severity of most patients may be mild in this study. Given that COPD is characteristic of progressive and irreversible airflow limitation with time, physicians should prospectively evaluate the episode frequency, the disease severity, and the necessity of using long-acting bronchodilators as an alternative or add-on therapy in the long-term follow-up.

Suboptimal adherence to bronchodilators, including oral and inhaled formulations, has been noted in COPD patients. ${ }^{22}$ Furthermore, several studies indicated that use of oral or inhaled short-acting bronchodilators may not be beneficial to health-related outcomes; ${ }^{23,24}$ however, use of inhaled long-acting bronchodilators with better adherence would reduce hospitalization. ${ }^{25,26}$ Similar to these findings, our study observed that patients received around only five bronchodilator prescriptions per year in outpatient settings, most of which were oral bronchodilators rather than inhaled forms. Furthermore, we found that with the increasing use of oral or inhaled short-acting bronchodilators rather than inhaled long-acting ones, the relative risk of hospitalization was slightly higher during the 1-year follow-up. This, again, 
reflects the importance of appropriate use of inhaled longacting bronchodilators and the necessity to improve COPD pharmaceutical care in Taiwan.

There are several limitations in this study. First, the lack of accuracy in diagnostic codes is a drawback of all claimsbased research. To address this issue, we restricted patients with COPD to those who simultaneously had corresponding diagnostic codes, prescription records of bronchodilators, and records of pulmonary function tests. This may partially minimize the possibility of coding errors or misdiagnoses, although we did not know the results of pulmonary function tests and did not exclude alternative diagnoses to COPD. Second, our study noted that among 23,396 patients initiating bronchodilators and with COPD diagnoses, only 4,387 patients (less than $20 \%$ ) received pulmonary function tests and were eligible in the analysis (Figure 1). This implied a potential underuse of pulmonary function tests; this has also been observed in the United States and Canada (less than 50\%). ${ }^{27,28}$ This would result in the inclusion of fewer potentially eligible individuals and limit the generalizability of this study. Furthermore, as per discussion, we had no pulmonary function test results from claims records. Instead, we applied resource utilization related to COPD episodes as a proxy to classify patients' diseases severity, which provided partial information to evaluate the appropriateness of the use of bronchodilators. ${ }^{29}$ Finally, we traced initiation claims records only for 1 year, which decreased heterogeneities and temporal fluctuations of disease severity among study individuals. However, long-term prescribing patterns should be explored in the further studies.

\section{Conclusion}

This study showed excessive use of oral bronchodilators in Taiwan during the past decades, which was not suggested in the guidelines recommendations. Further research is warranted to decrease inadequate oral bronchodilators and optimize inhaled treatments in management of patients with COPD.

\section{Acknowledgments}

This study was in part supported by the Taiwan Department of Health grant (DOH101-TD-B-111-01), which did not play any role in the study design, literature search, study selection, collection and analysis of data, interpretation of results, or drafting of the manuscript.

\section{Author contributions}

Study conception and design: YHD, CLH, CHC. Data acquisition: MSL. Data analysis and interpretation: YHD, CLH, YYL, CHC, MSL. Manuscript drafting: YHD, CLH.
Critical manuscript revision: YYL, CHC, MSL. CHC is the guarantor of the paper, had full access to all the data in the study, and takes responsibility for the integrity of the data and the accuracy of the data analysis. All the authors have read, contributed to, and approved the final manuscript and agreed to transfer the copyright ownership in the event of acceptance. YHD and CLH contributed equally to this manuscript.

\section{Disclosure}

The authors report no conflicts of interest in this work.

\section{References}

1. World Health Organization. World Health Statistics. Geneva: World Health Organization; 2014. Available from: http://www.who.int/gho/ publications/world_health_statistics/2014/en/. Accessed July 31, 2014

2. Curkendall SM, DeLuise C, Jones JK, et al. Cardiovascular disease in patients with chronic obstructive pulmonary disease, Saskatchewan Canada cardiovascular disease in COPD patients. Ann Epidemiol. 2006; 16(1):63-70.

3. Sidney S, Sorel M, Quesenberry CP Jr, DeLuise C, Lanes S, Eisner MD. COPD and incident cardiovascular disease hospitalizations and mortality: Kaiser Permanente Medical Care Program. Chest. 2005;128(4): 2068-2075.

4. Global Initiative for Chronic Obstructive Lung Disease (GOLD). Global Strategy for the Diagnosis, Management, and Prevention of COPD. GOLD; London, 2013. Available from: http://www.goldcopd.org/ guidelines-global-strategy-for-diagnosis-management.html. Accessed July 31, 2014.

5. Solem CT, Lee TA, Joo MJ, Lambert BL, Walton SM, Pickard AS. Complexity of medication use in newly diagnosed chronic obstructive pulmonary disease patients. Am J Geriat Pharmacother. 2012;10(2): 110.e1-122.e1

6. Corrado A, Rossi A. How far is real life from COPD therapy guidelines? An Italian observational study. Respir Med. 2012;106(7): 989-997.

7. Franssen FM, Spruit MA, Wouters EF. Determinants of polypharmacy and compliance with GOLD guidelines in patients with chronic obstructive pulmonary disease. Int J Chron Obstruct Pulmon Dis. 2011;6:493-501.

8. Glaab T, Banik N, Rutschmann OT, Wencker M. National survey of guideline-compliant COPD management among pneumologists and primary care physicians. COPD. 2006;3(3):141-148.

9. Esteban C, Moraza J, Quintana JM, Aburto M, Capelastegui A. Use of medication and quality of life among patients with COPD. Respir Med. 2006;100(3):487-495.

10. Roche N, Lepage T, Bourcereau J, Terrioux P. Guidelines versus clinical practice in the treatment of chronic obstructive pulmonary disease. Eur Respir J. 2001;18(6):903-908.

11. Lim S, Lam DC, Muttalif AR, et al. Impact of chronic obstructive pulmonary disease (COPD) in the Asia-Pacific region: the EPIC Asia population-based survey. Asia Pac Fam Med. 2015;14(1):4.

12. Harrold LR, Field TS, Gurwitz JH. Knowledge, patterns of care, and outcomes of care for generalists and specialists. J Gen Intern Med. 1999;14(8):499-511.

13. Sharif R, Cuevas CR, Wang Y, Arora M, Sharma G. Guideline adherence in management of stable chronic obstructive pulmonary disease. Respir Med. 2013;107(7):1046-1052.

14. Desalu OO, Onyedum CC, Adeoti AO, et al. Guideline-based COPD management in a resource-limited setting - physicians' understanding, adherence and barriers: a cross-sectional survey of internal and family medicine hospital-based physicians in Nigeria. Primary Care Respir J: J Gen Pract Airways Group. 2013;22(1):79-85. 
15. Asia Pacific COPD Roundtable Group. Global Initiative for Chronic Obstructive Lung Disease strategy for the diagnosis, management and prevention of chronic obstructive pulmonary disease: an Asia-Pacific perspective. Respirology. 2005;10(1):9-17.

16. Rau JL. Determinants of patient adherence to an aerosol regimen. Respir Care. 2005;50(10):1346-1356; discussion 57-59.

17. Kelloway JS, Wyatt RA, Adlis SA. Comparison of patients' compliance with prescribed oral and inhaled asthma medications. Arch Intern Med. 1994;154(12):1349-1352.

18. Salinas GD, Williamson JC, Kalhan R, et al. Barriers to adherence to chronic obstructive pulmonary disease guidelines by primary care physicians. Int J Chron Obstruct Pulmon Dis. 2011;6:171-179.

19. Aisanov Z, Bai C, Bauerle O, et al. Primary care physician perceptions on the diagnosis and management of chronic obstructive pulmonary disease in diverse regions of the world. Int J Chron Obstruct Pulmon Dis. 2012;7:271-282.

20. Oversteegen L, Rovini H, Belsey MJ. Respiratory drug market dynamics. Nat Rev Drug Discov. 2007;6(9):695-696.

21. Yasothan U, Kar S. Therapies for COPD. Nat Rev Drug Discov. 2008;7(4):285-286.

22. Taylor DR, Kinney CD, McDevitt DG. Patient compliance with oral theophylline therapy. Br J Clin Pharmacol. 1984;17(1):15-20.

23. Lee TA, Schumock GT, Bartle B, Pickard AS. Mortality risk in patients receiving drug regimens with theophylline for chronic obstructive pulmonary disease. Pharmacotherapy. 2009;29(9):1039-1053.
24. Corrao G, Zambon A, Faini S, Bagnardi V, Leoni O, Suissa S. Shortacting inhaled beta-2-agonists increased the mortality from chronic obstructive pulmonary disease in observational designs. J Clin Epidemiol. 2005;58(1):92-97.

25. Balkrishnan R, Christensen DB. Inhaled corticosteroid use and associated outcomes in elderly patients with moderate to severe chronic pulmonary disease. Clin Ther. 2000;22(4):452-469.

26. Vestbo J, Anderson JA, Calverley PM, et al. Adherence to inhaled therapy, mortality and hospital admission in COPD. Thorax. 2009; 64(11):939-943.

27. Damarla M, Celli BR, Mullerova HX, Pinto-Plata VM. Discrepancy in the use of confirmatory tests in patients hospitalized with the diagnosis of chronic obstructive pulmonary disease or congestive heart failure. Respir Care. 2006;51(10):1120-1124.

28. Gershon AS, Victor JC, Guan J, Aaron SD, To T. Pulmonary function testing in the diagnosis of asthma: a population study. Chest. 2012;141(5):1190-1196.

29. Wang YC, Lin JM, Li CY, Lee LT, Guo YL, Sung FC. Prevalence and risks of chronic airway obstruction: a population cohort study in Taiwan. Chest. 2007;131(3):705-710. 


\section{Supplementary materials}

Table SI Anatomical Therapeutic Chemical (ATC) classification system codes used to identify bronchodilator initiators

\begin{tabular}{|c|c|c|c|}
\hline Medication class & Therapeutic chemicals & ATC codes & Marketing year in Taiwan \\
\hline \multicolumn{4}{|l|}{ Oral bronchodilators } \\
\hline Oral beta- 2 agonists & Salbutamol & $\mathrm{R} 03 \mathrm{CCO} 2$ & 1974 \\
\hline Oral beta- 2 agonists & Terbutaline & $\mathrm{R} 03 \mathrm{CCO}$ & 1979 \\
\hline Oral beta- 2 agonists & Fenoterol & $\mathrm{R} 03 \mathrm{CCO} 4$ & 1979 \\
\hline Oral beta- 2 agonists & Hexoprenaline & $\mathrm{R} 03 \mathrm{CC} 05$ & 1982 \\
\hline Oral beta- 2 agonists & Procaterol & $\mathrm{R} 03 \mathrm{CC} 08$ & 1985 \\
\hline Oral beta- 2 agonists & Trimetoquinol & R03CC09 & 1975 \\
\hline Oral beta- 2 agonists & Bambuterol & $\mathrm{R} 03 \mathrm{CCl} 2$ & 1993 \\
\hline Oral beta- 2 agonists & Clenbuterol & $\mathrm{R} 03 \mathrm{CCl} 3$ & 1988 \\
\hline Oral beta- 2 agonists & Formoterol & R03CC9I & 1993 \\
\hline Oral xanthines & Theophylline & R03DA04 & 1972 \\
\hline Oral xanthines & Aminophylline & R03DA05 & 1970 \\
\hline \multicolumn{4}{|c|}{ Inhaled short-acting bronchodilators } \\
\hline SABAs & Salbutamol & $\mathrm{R} 03 \mathrm{ACO} 2$ & 1989 \\
\hline SABAs & Terbutaline & $\mathrm{R} 03 \mathrm{AC} 03$ & 1989 \\
\hline SABAs & Fenoterol & $\mathrm{R} 03 \mathrm{AC} 04$ & 1992 \\
\hline SABAs & Hexoprenaline & R03AC06 & 1995 \\
\hline SAMAs & Ipratropium & R03BB0I & 1981 \\
\hline SABA/SAMA FDCs ${ }^{\mathrm{a}}$ & Fenoterol/lpratropium & R03AK03 & 1986 \\
\hline SABA/SAMA FDCs ${ }^{\mathrm{a}}$ & Salbutamol/lpratropium & R03AK04 & 2000 \\
\hline \multicolumn{4}{|c|}{ Inhaled long-acting bronchodilators } \\
\hline LABAs & Salmeterol & $\mathrm{R} 03 \mathrm{ACI} 2$ & 1996 \\
\hline LABAs & Formoterol & $\mathrm{R} 03 \mathrm{ACI} 3$ & 2000 \\
\hline LABAs & Procaterol & $\mathrm{R} 03 \mathrm{ACI} 6$ & 1989 \\
\hline LABAs & Indacaterol & $\mathrm{R} 03 \mathrm{ACI} 8$ & 2010 \\
\hline LAMAs & Tiotropium & R03BB04 & 2003 \\
\hline LABA/ICS FDCs & Salmeterol/Fluticasone & R03AK06 & 2001 \\
\hline LABA/ICS FDCs & Formoterol/Budesonide & R03AK07 & 2001 \\
\hline
\end{tabular}

Notes: aPrescriptions with SABA/SAMA FDCs were simultaneously assigned into use of SABAs and use of SAMAs.

Abbreviations: FDCs, fixed dose combinations; ICS, inhaled corticosteroids; LABAs, long-acting beta-2 agonists; LAMAs, long-acting muscarinic antagonists; SABAs, shortacting beta agonists; SAMAs, short-acting muscarinic antagonists.

Table S2 International Classification of Diseases, 9th Revision, Clinical modification (ICD-9-CM) diagnostic codes used to identify comorbidities among bronchodilator initiators at baseline

\begin{tabular}{|c|c|}
\hline Comorbidities & ICD-9-CM codes \\
\hline Hypertension & 401 \\
\hline Hypertensive heart/renal disease & $402-404$ \\
\hline Ischemic heart disease/angina & $4 I I, 4 I 3,4 I 4$ \\
\hline Myocardial infarction & 410,412 \\
\hline Coronary revascularization ${ }^{\mathrm{a}}$ & $\begin{array}{l}\text { 68023A, 68023B, 68024A, 68024B, 68025A, 68025B, 83064AI, 9790IK, } \\
\text { 97902A, 97903B, 97906K, 97907A, 97908B, 979IIK, 979I2A, 979I3B, 979I6K, } \\
979 I 7 A, 979 I 8 B, 33076 \mathrm{~A}, 33076 \mathrm{~B}, 33077 \mathrm{~A}, 33077 \mathrm{~B}, 33078 \mathrm{~A}, 33078 \mathrm{~B}, 975 \mathrm{IIK} \text {, } \\
\text { 975IIA, 975I3B, 975I6K, 975I7A, 975I8B, 9752IK, 97522A, 97523B }\end{array}$ \\
\hline Cardiac dysrhythmia & 427 \\
\hline Atrial fibrillation & 427.3 \\
\hline Congestive heart failure & 428 \\
\hline Cerebrovascular disease & $433,434,436-438$ \\
\hline Ischemic/hemorrhagic stroke & $430-434,436$ \\
\hline Transient ischemic attack & 435 \\
\hline Peripheral vascular disease & $440.21,443$ \\
\hline Diabetes mellitus & 250 \\
\hline Pneumonia, influenza, and acute bronchitis & $480-487,466$ \\
\hline Rheumatoid arthritis/osteoarthritis & $710,714,715,720$ \\
\hline Any cancer (except lung cancer) & $|40-16|, \mid 63-208$ \\
\hline Lung cancer & 162 \\
\hline Depressive disorder & 296.2, 296.3, 298.0, 300.4, 309.0, 309.I, 293.83, 296.90, 309.28, 296.82, 31। \\
\hline
\end{tabular}

Notes: aBased on National Health Insurance service claims codes (http://www.nhi.gov.tw/query/query2.aspx? menu=20\&menu_id=710\&webdata_id=3633\&WD_ID=900 accessed October, 2013). 
Table S3 Device types of inhaled bronchodilators over I year in total bronchodilator initiators and stratified by the years of index dates

\begin{tabular}{|c|c|c|c|c|}
\hline & \multirow{2}{*}{$\begin{array}{l}\text { Total } \\
\text { initiators }\end{array}$} & \multicolumn{3}{|c|}{ Years of index dates } \\
\hline & & $200 I-2003$ & $2004-2006$ & $2007-2010$ \\
\hline Number of inhaled bronchodilator prescriptions & 4,096 & 1,812 & $\mathrm{I}, 033$ & $\mathrm{I}, 25 \mathrm{I}$ \\
\hline \multicolumn{5}{|l|}{ By devices ${ }^{\mathrm{a}}$, \% } \\
\hline Nebulizers & 22.73 & 17.05 & 24.78 & 29.26 \\
\hline Metered dose inhalers & 55.44 & 69.37 & $5 \mathrm{I.31}$ & 38.69 \\
\hline Dry powder inhalers & 30.10 & 20.86 & 32.91 & 41.17 \\
\hline
\end{tabular}

Notes: aProportions added up to more than 100\% because patients may receive multiple inhaled bronchodilators during the I-year follow-up period.

Table S4 Use of bronchodilators and the association with hospitalization in the follow-up I year

\begin{tabular}{|c|c|c|c|c|}
\hline & $\begin{array}{l}\text { Total initiators } \\
(n=4,387)\end{array}$ & $\begin{array}{l}\text { Patients hospitalized } \\
(n=1,289)\end{array}$ & $\begin{array}{l}\text { Patients without } \\
\text { hospitalization }(n=3,098)\end{array}$ & $\mathrm{OR}^{\mathrm{a}}(95 \% \mathrm{Cl})$ \\
\hline \multicolumn{5}{|c|}{ Use of bronchodilators, mean (SD) } \\
\hline Any bronchodilators & $4.86(5.14)$ & $6.30(6.14)$ & $4.26(4.54)$ & $1.05(1.03-1.06)$ \\
\hline Oral bronchodilators & $4.48(4.96)$ & $5.69(5.89)$ & $3.98(4.43)$ & $1.04(1.03-1.06)$ \\
\hline Oral xanthines & $3.04(4.20)$ & $3.97(5.07)$ & $2.66(3.72)$ & $1.05(1.03-1.06)$ \\
\hline Oral beta- 2 agonists & $2.31(3.67)$ & $2.76(4.14)$ & $2.12(3.44)$ & $1.03(1.01-1.05)$ \\
\hline Inhaled bronchodilator & $0.93(2.28)$ & I.3। (2.79) & $0.78(2.03)$ & $1.07(1.03-1.09)$ \\
\hline Short-acting & $0.64(1.76)$ & $1.05(2.34)$ & $0.47(1.43)$ & $1.12(1.08-1.17)$ \\
\hline Long-acting & $0.36(1.52)$ & $0.33(1.50)$ & $0.37(1.52)$ & $0.98(0.94-1.03)$ \\
\hline LABAs & $0.06(0.53)$ & $0.05(0.50)$ & $0.06(0.54)$ & $1.03(0.90-1.17)$ \\
\hline LABA/ICS FDCs & $0.21(0.11)$ & $0.20(\mathrm{I} . \mathrm{II})$ & $0.22(\mathrm{I} . \mathrm{II})$ & $0.98(0.90-1.17)$ \\
\hline LAMAs & $0.11(0.93)$ & $0.11(0.89)$ & $0.11(0.95)$ & $0.98(0.91-1.06)$ \\
\hline
\end{tabular}

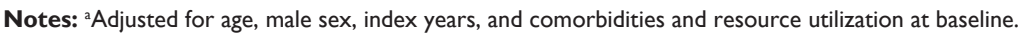

Abbreviations: $\mathrm{Cl}$, confidence interval; FDCs, fixed dose combinations; ICS, inhaled corticosteroids; LABAs, long-acting beta-2 agonists; LAMAs, long-acting muscarinic antagonists; OR, odds ratio.

\section{Publish your work in this journal}

The International Journal of COPD is an international, peer-reviewed journal of therapeutics and pharmacology focusing on concise rapid reporting of clinical studies and reviews in COPD. Special focus is given to the pathophysiological processes underlying the disease, intervention programs, patient focused education, and self management protocols.

\section{Dovepress}

This journal is indexed on PubMed Central, MedLine and CAS. The manuscript management system is completely online and includes a very quick and fair peer-review system, which is all easy to use. Visit $\mathrm{http}: / / \mathrm{www}$. dovepress.com/testimonials.php to read real quotes from published authors. 